\title{
Maternal Age at Childbirth and Parental Reports of Attention-Deficit/Hyperactivity Disorder and Learning Disability, Ages 4 to 15 Years
}

\section{Yong Chen}

Nanjing Medical University

\section{Siyu $\mathrm{Ma}$}

Nanjing Medical University

Haobin Huang

Nanjing Medical University

Weiwei Duan ( $\nabla$ passion@njmu.edu.cn )

Nanjing Medical University

Xuming Mo

Nanjing Medical University

\section{Research Article}

Keywords: Maternal age, attention-deficit/hyperactivity disorder, learning disability, NHANES

Posted Date: January 27th, 2021

DOI: https://doi.org/10.21203/rs.3.rs-152344/v1

License: (c) (1) This work is licensed under a Creative Commons Attribution 4.0 International License. Read Full License 


\section{Abstract}

Background: Studies have shown that young maternal age at childbirth can increase the risk of attentiondeficit/hyperactivity disorder (ADHD) in the offspring, but a study of the U.S. population has not been reported. Moreover, there is no reported research on young and advanced maternal age at childbirth and on whether it can contribute to learning disability (LD) risk for offspring.

Methods: This study evaluated the association between young and advanced maternal age at childbirth and offspring ADHD and LD risk in the U.S. population. Using data from 8,098 participants from the National Health and Nutrition Examination Survey (NHANES) conducted in 1999-2004, we analyzed the association between maternal age at childbirth and ADHD and LD risks in offspring. Odd ratios (ORs) and $95 \%$ confidence intervals (Cls) for maternal age at childbirth in association with ADHD and LD risks in offspring were estimated using multivariate logistic regression models after adjustment for age, gender, race, body mass index (BMI), family income, smoking during pregnancy, and NHANES cycles. Restricted cubic spline (RCS) models were used to evaluate potential nonlinear relationships. Sensitivity analysis were performed to ensure the reliability of the results.

Results: Among all participants, the offspring of subjects with a maternal age at childbirth of 18-24 years had an increased risk of ADHD (OR=1.34, 95\% Cl: 1.01, 1.79), LD $(\mathrm{OR}=1.36,95 \% \mathrm{Cl}: 1.06,1.79)$ or both ADHD and LD (OR=1.48, 95\% $\mathrm{Cl}: 1.20,1.81)$. Additionally, compared with subjects with a maternal age of 25-29 years, subjects with a maternal age of 35-39 years had lower odds of having offspring with $\mathrm{ADHD}(\mathrm{OR}=0.60,95 \% \mathrm{Cl}: 0.36,1.00)$ and higher odds of having offspring with $\mathrm{LD}(\mathrm{OR}=1.34,95 \% \mathrm{Cl}$ : $1.01,1.78)$. The relationship between maternal age at childbirth and LD risk presents a U-shaped curve. Additionally, the risk of ADHD and LD caused by maternal age at childbirth appears to be affected by gender.

Conclusions: These results provide epidemiological evidence showing that young and advanced maternal age at childbirth are associated with ADHD and LD risks.

\section{Introduction}

Maternal age at childbirth is considered as the age of the mother at the time of delivery. Generally, young maternal age at childbirth is defined as being 19 years old or younger, and advanced maternal age is defined as being at least 35 years old [1]. The effects of young and advanced maternal age at childbirth may affect the health outcomes of mothers and offspring. Previous studies have suggested that young maternal age at childbirth is associated with maternal cardiovascular disease risk [2] and low birth weight, preterm birth, and neonatal mortality [3]. Several adverse health effects are associated with advanced maternal age at childbirth, for example, cerebral palsy, neurocognitive disorders, psychiatric disorders [4], and stillbirth risk [5-7] in offspring and maternal cancer risk [8, 9]; however, some studies have observed that advanced maternal age did not seem to be associated with the long-term morbidity of the offspring [10]. 
Neurological disorders in children manifest as abnormalities in neurocognition, self-regulation, and adaptive functioning [11]. Abnormal neurobehavioral function in children can cause health problems and other issues, such as emotional disorders [12], lower education levels [13], anti-social behavior [14], and premature mortality [15]. Among these disorders, attention-deficit/hyperactivity disorder (ADHD) and learning disability (LD) are common neurological disorders in children. ADHD and LD are defined as persistent inattention and hyperactivity and as a reduced ability to learn, respectively. The global prevalence of $A D H D$ in children is approximately $5 \%$ [16], and the prevalence was reported as $18.1 \%$ in Tunisian adolescents [17], 8.8\% in Nigerian residents [18], and 6.26\% in Chinese children and teenagers [19]. The prevalence rates of LD in the U.S. and in a city in India were found to be $9.7 \%$ [20] and 3.08\% [21], respectively. Previous studies on the risk factors for ADHD and LD mainly focused on genetic factors $[15,22-24]$, while approximately $10-40 \%$ of the risk may be related to environmental factors, such as premature birth and smoking during pregnancy for $\operatorname{ADHD}[25,26]$ and low birth weight [27], maternal BMI before pregnancy [28], and maternal anemia [29] for LD. Although many previous studies have suggested that ADHD is highly related to hereditary factors, no gene with a definite pathogenic effect has been found [30]. Although Thapar et al found that both prenatal and perinatal factors may be risk factors of ADHD and LD [15], these risk factors are not fully understood. Therefore, fully understanding these risk factors may effectively prevent the occurrence of ADHD and LD.

A recent study found that young maternal age at childbirth is positively correlated with the risk of ADHD in offspring in Denmark [31]. However, there is a lack of relevant research in the U.S. Because the U.S. has immigrants from multiple countries, the genetic background and cultural differences of the population are different from those of Denmark. Additionally, the prevalence of ADHD is much higher in the U.S. than the average level globally [32]. The average maternal age at first childbirth increased both from 1970 to 2006 and from 2011 and 2012 in the U.S. [33]. This study was performed due to the lack of U.S. research on the association between maternal age at childbirth and ADHD and LD risk for offspring. This study is the first to explore the association between maternal age at childbirth and ADHD and LD in offspring and to evaluate its nonlinear relationship in the U.S.

\section{Method}

\section{Study population}

The National Health and Nutrition Examination Survey (NHANES) is conducted by the National Center for Health Statistics (NCHS) at the Centers for Disease Control and Prevention every two years, and the main purpose is to assess the health and nutritional status of children and adults in the U.S.. The user data agreement is available online (https://www.cdc.gov/nchs/data_access/restrictions.htm). The NCHS Research Ethics Review Board approved these NHANES cycles. All subjects provided written informed consent. Data on ADHD and LD outcomes are available only in 1999-2004; thus, we obtained publicly available NHANES data generated through surveys conducted in 1999-2004, including data from a total of 31,126 participants. By using unique survey participant identifiers, we combine information on their characteristics with the questionnaire information. For maternal age at childbirth, data are available only 
for offspring aged 0 to 15 years, and the age range for ADHD and LD evaluation were 4-19 years and 415 years, respectively. We therefore excluded participants under age 4 and over age 15 . Although pregnancy may affect the outcomes of analysis, we did not exclude pregnant subjects $(n=7)$ in our analysis. Finally, 8,098 subjects were included in our study: 3,977 boys and 4,121 girls. The flow chart for inclusion and exclusion is listed in Fig. 1.

\section{Assessment of maternal age at childbirth and ADHD and LD}

This information was based on parental/guardian responses to the following NHANES interview questions, asked twice for both LD and ADHD (for children $\leq 15$ years of age): "How old was your biological mother when you were born?". Age was recorded as a continuous variable. The outcomes of ADHD and LD were obtained from parental reports of LD and/or ADHD. Specifically, the data were based on parental/guardian responses to two NHANES interview questions: "Has a doctor or health professional ever told you that you had attention deficit disorder?" and "Has a representative from a school or a health professional ever told you that you had a learning disability?" For children $\geq 4$ years old, the same questions were asked for both LD and ADHD. The answer to both of these questions was "yes" or "no". The answer was included as a binary variable for subsequent analysis. We divided children into those with parental/guardian reports of ADHD, those with LD, and those with LD and ADHD.

\section{Covariates}

Several factors related to outcomes were adjusted in our logistic regression analysis, including age (continuous variable), gender (categorical variable), race (categorical variable), body mass index (BMI, continuous variable), family income (continuous variable), and NHANES cycle (categorical variable). Information regarding age, gender, race, and family income was obtained by questionnaires in face-toface interviews. Height and body weight were recorded in a physical examination and were used to calculate the BMI. Information related to smoking during pregnancy was based on parental/guardian responses to a questionnaire. The following question was asked: "Did your biological mother smoke at any time while she was pregnant?".

\section{Statistical method}

Continuous variables are presented as the mean and standard deviation, and categorical variables are presented as the frequency and percentage. Because the variables BMI and family income were missing for 429 and 686 participants, respectively, in order to ensure that the sample size was not reduced, we used the mean value imputation method. We divided maternal age at childbirth into the following groups: $\leq 17$ years, $18-24$ years, $25-29$ years, $30-34$ years, $35-39$ pairs, and $\geq 40$ years. Considering that both young and advanced maternal age at childbirth may be risk factors for ADHD or LD, we regarded 25-29 years as the reference age [34]. Logistic regression was used to assess the association between maternal 
age at childbirth and ADHD, LD and ADHD + LD after adjusting for age, gender, race, BMI, family income, and NHANES cycle. We also used stratification analysis to explore the differences in this association between different genders and races. In addition, we used restricted cubic spline (RCS) regression to investigate the nonlinear trend between maternal age at childbirth and the risk of ADHD, LD and ADHD + LD. For the sensitivity analysis, in the selection of covariates of logistic regression, we excluded BMI and NHANES cycle. $P<0.05$ was considered a statistically significant difference. In multiple comparisons, to avoid false positives, the Bonferroni correction was used in our analysis, with $\mathrm{P}$ values less than $(0.05 / 5$ [group] $=0.01$ ) considered statistically significant.

\section{Results}

The average maternal age at childbirth in our study was $25.6 \pm 6.1$ years old (Table 1). Maternal age at childbirth differs among races; this age was lowest in the non-Hispanic Black population (24.5 \pm 6.1 years old) and highest in the non-Hispanic White population ( $27.3 \pm 5.8$ years old). Subjects with high family income had a higher maternal age at childbirth on average than those with low family income $(27.4 \pm 5.8$ vs $24.0 \pm 6.0, P<0.001)$. In addition, maternal age at childbirth did not differ significantly on the basis of smoking during pregnancy $(25.6 \pm 6.0$ vs $25.6 \pm 6.1, P=0.961)$. 
Table 1

Characteristics of maternal age of children included in the study (NHANES 1999$2004 ; n=8,098)$.

\begin{tabular}{|c|c|c|c|}
\hline Characteristic & $\mathbf{N}(\%)$ & Mean \pm SD & $P$ value \\
\hline Overall & $8,098(100.0 \%)$ & $25.6 \pm 6.1$ & \\
\hline Gender & & & 0.044 \\
\hline Boys & $3,977(49.1 \%)$ & $25.4 \pm 6.1$ & \\
\hline Girls & $4,121(50.9 \%)$ & $25.7 \pm 6.1$ & \\
\hline Race/Ethnicity & & & $<0.001$ \\
\hline Mexican American & $2,700(33.3 \%)$ & $25.1 \pm 5.8$ & \\
\hline Other Hispanic & $347(4.3 \%)$ & $25.9 \pm 6.5$ & \\
\hline Non-Hispanic White & $2,168(26.8 \%)$ & $27.3 \pm 5.8$ & \\
\hline Non-Hispanic Black & $2,541(31.4 \%)$ & $24.5 \pm 6.1$ & \\
\hline Other Race - Including Multi-Racial & $342(4.2 \%)$ & $26.5 \pm 6.2$ & \\
\hline Smoking During Pregnancy & & & 0.961 \\
\hline Yes & $1,162(14.3 \%)$ & $25.6 \pm 6.0$ & \\
\hline No & $6,880(85.0 \%)$ & $25.6 \pm 6.1$ & \\
\hline Age (years) & & & 0.002 \\
\hline $4-7$ & $2,303(28.4 \%)$ & $26.0 \pm 6.3$ & \\
\hline $8-11$ & $2,217(27.4 \%)$ & $25.5 \pm 6.0$ & \\
\hline $12-15$ & $3,578(44.2 \%)$ & $25.4 \pm 6.0$ & \\
\hline NHANES cycle & & & 0.028 \\
\hline 1999-2000 & $2,691(33.2 \%)$ & $25.3 \pm 6.0$ & \\
\hline $2001-2002$ & $2,874(35.5 \%)$ & $25.8 \pm 6.1$ & \\
\hline $2003-2004$ & $2,533(31.3 \%)$ & $25.6 \pm 6.2$ & \\
\hline PIR & & & $<0.001$ \\
\hline$<1.08$ & $2,711(33.5 \%)$ & $24.0 \pm 6.0$ & \\
\hline $1.08-2.17$ & $2,700(33.3 \%)$ & $25.3 \pm 6.0$ & \\
\hline$>2.17$ & $2,687(33.2 \%)$ & $27.4 \pm 5.8$ & \\
\hline
\end{tabular}

Table 2 suggests that the percentages of offspring with ADHD, LD and ADHD + LD in our study are $6.4 \%$, $10.4 \%$ and $13.5 \%$, respectively. The maternal age at childbirth for offspring who had ADHD, LD, or ADHD 
+ LD was younger than that for offspring who did not have ADHD, LD, or ADHD + LD (25.2 vs 26.7, P = 0.001 for $A D H D ; 25.7$ vs $26.6, P<0.001$ for $L D ; 25.5$ vs $26.7, P<0.001$ for $A D H D+L D)$.

Table 2

Mean maternal age at childbirth based on outcomes for study participants $(\mathrm{n}=$ 8,098).

\begin{tabular}{|llll|}
\hline Neurodevelopmental outcome & $\mathbf{N}(\%)$ & Mean $(95 \% \mathrm{Cl})$ & P value \\
\hline ADHD & & & 0.001 \\
\hline Yes & $521(6.4 \%)$ & $25.2(24.3,26.0)$ & \\
\hline No & $7,561(93.6 \%)$ & $26.7(26.3,27.0)$ & \\
\hline LD & & $<0.001$ \\
\hline Yes & $841(10.4 \%)$ & $25.7(25.2,26.3)$ & \\
\hline No & $7,245(89.6 \%)$ & $26.6(26.3,27.0)$ & \\
\hline ADHD + LD & & & \\
\hline Yes & & & \\
\hline No & $1,090(13.5 \%)$ & $25.5(24.9,26.2)$ & \\
\hline Weighted mean. & $7,008(86.5 \%)$ & $26.7(26.4,27.0)$ & \\
\hline ADHD, attention-deficit/hyperactivity disorder; LD, learning disability. & \\
\hline
\end{tabular}

The logistic regression results showed that compared to subjects aged 25-29 years, the risk of ADHD, LD, and both ADHD and LD in offspring was increased in subjects younger than 25 years old and older than 39 years old at childbirth (Table 3 ) after adjusting for age, gender, race, BMI, family income, smoking during pregnancy, and NHANES cycle. Among these groups, the adjusted OR for subjects aged 18-24 years was $1.48(95 \% \mathrm{Cl}: 1.20,1.81)$ for the risk of both ADHD and LD in offspring, with a P value less than 0.01 (Bonferroni adjustment of the $P$ value). In addition, we also observed that compared to subjects aged 25-29 years at childbirth, the risk of ADHD was reduced, while the LD risk and the risk of both $A D H D$ and $L D$ in offspring was increased among people aged 30-39 years. However, these results were not statistically significant, which may be related to our small sample size. The sensitivity analysis showed that the results are robust (Table S1). 
Table 3

Association between maternal age at childbirth and parent-reported LD, ADHD, and both LD and ADHD.

\begin{tabular}{|c|c|c|c|c|c|c|c|}
\hline & & $\leq 17$ & $18-24$ & $\begin{array}{l}25- \\
29\end{array}$ & $30-34$ & $35-39$ & $\geq 40$ \\
\hline \multirow[t]{3}{*}{ ADHD } & $\begin{array}{l}\text { Model } \\
1\end{array}$ & $\begin{array}{l}1.08(0.72, \\
1.62)\end{array}$ & $\begin{array}{l}1.38(1.04, \\
1.84)\end{array}$ & 1 & $\begin{array}{l}0.93(0.61, \\
1.43)\end{array}$ & $\begin{array}{l}0.56(0.34, \\
0.93)\end{array}$ & $\begin{array}{l}1.30(0.49 \\
3.48)\end{array}$ \\
\hline & $\begin{array}{l}\text { Model } \\
2\end{array}$ & $\begin{array}{l}1.15(0.75, \\
1.78)\end{array}$ & $\begin{array}{l}1.39(1.04 \\
1.84)\end{array}$ & 1 & $\begin{array}{l}0.95(0.62, \\
1.46)\end{array}$ & $\begin{array}{l}0.58(0.35 \\
0.97)\end{array}$ & $\begin{array}{l}1.34(0.50 \\
3.55)\end{array}$ \\
\hline & $\begin{array}{l}\text { Model } \\
3\end{array}$ & $\begin{array}{l}1.04(0.68 \\
1.60)\end{array}$ & $\begin{array}{l}1.34(1.01 \\
1.79)\end{array}$ & 1 & $\begin{array}{l}0.99(0.63 \\
1.53)\end{array}$ & $\begin{array}{l}0.60(0.36 \\
1.00)\end{array}$ & $\begin{array}{l}1.48(0.56 \\
3.93)\end{array}$ \\
\hline \multirow[t]{3}{*}{ LD } & $\begin{array}{l}\text { Model } \\
1\end{array}$ & $\begin{array}{l}2.05(1.30 \\
3.25)\end{array}$ & $\begin{array}{l}1.58(1.20 \\
2.08)\end{array}$ & 1 & $\begin{array}{l}1.23(0.85 \\
1.78)\end{array}$ & $\begin{array}{l}1.18(0.90 \\
1.56)\end{array}$ & $\begin{array}{l}1.98(0.80 \\
4.92)\end{array}$ \\
\hline & $\begin{array}{l}\text { Model } \\
2\end{array}$ & $\begin{array}{l}1.69(1.07, \\
2.67)\end{array}$ & $\begin{array}{l}1.39(1.06, \\
1.83)\end{array}$ & 1 & $\begin{array}{l}1.35(0.94 \\
1.95)\end{array}$ & $\begin{array}{l}1.31(0.99, \\
1.74)\end{array}$ & $\begin{array}{l}2.34(0.97 \\
5.70)\end{array}$ \\
\hline & $\begin{array}{l}\text { Model } \\
3\end{array}$ & $\begin{array}{l}1.61(0.99, \\
2.62)\end{array}$ & $\begin{array}{l}1.36(1.02, \\
1.79)\end{array}$ & 1 & $\begin{array}{l}1.41(0.96 \\
2.05)\end{array}$ & $\begin{array}{l}1.34(1.01, \\
1.78)\end{array}$ & $\begin{array}{l}2.59(1.05 \\
6.35)\end{array}$ \\
\hline \multirow[t]{3}{*}{$\begin{array}{l}\text { ADHD } \\
+\angle D\end{array}$} & $\begin{array}{l}\text { Model } \\
1\end{array}$ & $\begin{array}{l}1.88(1.35 \\
2.61)\end{array}$ & $\begin{array}{l}1.63(1.34 \\
1.98)\end{array}$ & 1 & $\begin{array}{l}1.12(0.81, \\
1.55)\end{array}$ & $\begin{array}{l}1.05(0.80 \\
1.39)\end{array}$ & $\begin{array}{l}1.91(0.86, \\
4.24)\end{array}$ \\
\hline & $\begin{array}{l}\text { Model } \\
2\end{array}$ & $\begin{array}{l}1.72(1.23, \\
2.39)\end{array}$ & $\begin{array}{l}1.52(1.25 \\
1.85)\end{array}$ & 1 & $\begin{array}{l}1.18(0.86, \\
1.63)\end{array}$ & $\begin{array}{l}1.12(0.84, \\
1.50)\end{array}$ & $\begin{array}{l}2.13(0.98, \\
4.63)\end{array}$ \\
\hline & $\begin{array}{l}\text { Model } \\
3\end{array}$ & $\begin{array}{l}1.59(1.12 \\
2.28)\end{array}$ & $\begin{array}{l}1.48(1.20 \\
1.81)^{\star}\end{array}$ & 1 & $\begin{array}{l}1.23(0.89 \\
1.70)\end{array}$ & $\begin{array}{l}1.15(0.85, \\
1.54)\end{array}$ & $\begin{array}{l}2.35(1.09 \\
5.09)\end{array}$ \\
\hline
\end{tabular}

Model 1 adjusted for age and gender.

Model 2 adjusted for age, gender, race, body mass index (BMI), and PIR.

Model 3 adjusted for age, gender, race, BMI, PIR, smoking during pregnancy, and NHANES cycle.

* the $P$ value was less than the Bonferroni adjustment (0.010).

Our analysis was further subjected to stratification by gender and race. We found that subjects aged 3539 years had a higher risk of LD in female offspring than did subjects aged $25-29$ years $(O R=1.67 ; 95 \%$ $\mathrm{Cl} 1.14,2.45, \mathrm{P}=0.009$ ), and the risk of both ADHD and LD for boys was higher for subjects aged 18-24 years than for those aged $25-29$ years at childbirth $(\mathrm{OR}=1.60 ; 95 \% \mathrm{Cl} 1.26,2.04, \mathrm{P}<0.001)$ (Fig. 2).

When maternal age at childbirth was considered as a continuous variable using RCS regression models (Fig. 3), a U-shaped association of maternal age at childbirth with the risk of ADHD + LD was observed (P value $=0.007)$. The risk of ADHD + LD was lowest among subjects aged 25-29 years. When performing RCS regression models of the LD risk outcome, we found a similar but more pronounced U-shaped curve with a greater slope $(P$ value $=0.005)$. However, the nonlinear association between maternal age at childbirth and ADHD was not significant $(P$ value $=0.842)$. 


\section{Discussion}

This was one of the first studies finding that young maternal age at childbirth in the U.S. population may increase the risk of ADHD and LD in offspring and that advanced maternal age at childbirth seems likely to increase the risk of LD in offspring. In addition, we also found that these associations differ by gender. Furthermore, the relationship between maternal age at childbirth and the risk of LD in offspring presents a U-shaped curve.

Previous epidemiological studies have shown an increased risk of ADHD in the offspring of mothers with young maternal age at childbirth in the Swedish population [35]; similarly, the risk of ADHD in offspring is also increased for mothers with young maternal age at childbirth in the Danish population [31]. The results of the above two studies are similar to ours and may be explained because the development of ADHD is related to neurotransmission pathways. Therefore, we speculated that the education levels of the subjects with advanced maternal age at childbirth were higher, and these individuals may have greater health knowledge during pregnancy. Therefore, compared to the 25-29-year-old group, participants with advanced maternal age may pay more attention to nutritional supplements and additives during pregnancy, such as folic acid, which are beneficial for neural development, thus reducing the risk of $A D H D$ in their offspring. Other potential reasons are that there are complex ethnic backgrounds in the U.S.; the genetic backgrounds of different races are quite different, and genetic factors are considered to be related to the development of $\operatorname{ADHD}[36,37]$. In contrast to the results of the present study, a study of the Danish population revealed that advanced maternal age at childbirth (over 35 years old) is a protective factor against ADHD in offspring. While our results showed that the risk of ADHD in offspring of individuals older than 39 is likely to be increased, the difference was not significant, which may be related to the small sample size of our study. Another reason for the difference in study results is that the Danish study did not group and analyze the data of people over 40 years old.

At present, few studies have been conducted on maternal age at childbirth and LD risk in offspring, which may be related to the diagnosis of LD without International Classification of Disease (ICD) standards. Although LD evaluation is subjective, its evaluation is easy to perform and can reflect certain neural functions $[38,39]$. At present, the etiology of LD is still unclear. Some scholars have suggested that genetic factors may play a role, and the symptoms of LD are also broader. Adolescents who exhibit abnormalities in reading, writing, listening, speaking, and performing math in will be suggested to have LD. However, the cause of LD in offspring is complex and may not be related to a neural pathway. In this study, we observed a U-shaped curve of maternal age at childbirth and offspring LD risk. It is suggested that the individuals with younger and more advanced maternal ages at childbirth will have a greater risk of having offspring with LD. At present, most of the existing studies suggest that young maternal age at childbirth increases the risk of health effects on offspring. However, controversy exists for subjects with advanced maternal age at childbirth. Appropriate older age of mother is beneficial for the offspring with regard to financial status and education [1]. The social economic position and resources of older mothers are greater than those of younger mothers, and over time, the offspring of older mothers experience the effects of improvements in public health conditions and educational expansion. Although negative 
effects occur during the perinatal period, there is no difference between these offspring and offspring of mothers with a younger age at childbirth during adulthood [40]. However, it should be noted that the oocytes of older mothers are aging, and accumulated DNA damage [41] and the imbalance in mitochondrial homeostasis [42] in aging oocytes have a negative impact on the development of fertilized eggs [43]. DNA damage and mitochondrial function are closely related to nerve development [44, 45]. These characteristics of aging oocytes may explain the decreased learning ability of offspring. However, some researchers suggest that some patients are classified as having LD because of their parents' misunderstanding of the education process and the parents have higher expectations for their offspring [46]. The intelligence or neurodevelopment of offspring may not be abnormal, but the specific molecular mechanism of the relationship between age and LD still requires further research.

Our results indicate that maternal age at childbirth is related to the risk of offspring LD. Due to the recall bias in retrospective cohorts, animal studies may clarify the cause and effect relationship. Some existing mechanistic studies have confirmed that the spatial learning capacity of mice at 32-35 weeks is lower than that of mice at 9-12 weeks, which may be related to the decrease in the expression of vitamin $D$ receptor (VDR) in the early embryogenesis process [47]. In addition, compared with 3-month-old mice, 1518-month-old mice showed anxiety-like behavior, and the gene expression pattern of the hippocampus also changed [48]. We also speculated that late production age may be related to the egg quality [49]. These possible mechanisms may explain the link between maternal age at childbirth and ADHD and LD risks in offspring. However, there are few studies on the mechanism of the relationship between young maternal age at childbirth and ADHD and LD risk, possibly because few animal models exist. We speculated that the link between young maternal age at childbirth and ADHD and LD risk may arise because the family income and education levels of young mothers are lower than those of older mothers [50]. Additionally, Fall et a/ found that young maternal age at childbirth may be associated with poor birth outcomes and nutrition for offspring in low- and middle-income countries [1].

Our results also showed a sex difference in the association of young maternal age at childbirth and the risk of $A D H D+L D$ among male and female offspring. The reason for this phenomenon is that the ADHD incidence rate of boys is higher than that girls $[15,30]$. Additionally, sex differences in gonadal steroid hormone levels during perinatal development result in gender differences in neurodevelopment. Furthermore, compared to early-adolescent and middle-aged mice, male offspring have less developed sexual organs [51], which suggests that androgen may also be low in early-adolescent mice, and changes in hormones in adolescence are related to brain volume and neurodevelopment [52]. Therefore, we speculate that hormonal disorders in the male offspring of young age mothers may cause an neurodevelopmental abnormality that leads to the increased risk of both ADHD and LD in boys rather than girls.

As an advantage, this study is the first to report the association between maternal age at childbirth and offspring ADHD and LD risks in the U.S. population. We found that young or advanced maternal age at childbirth may lead to ADHD and LD risks in offspring. Through the results of subgroup analysis, we identified the susceptible population, which may provide a basis for research on the underlying

Page 10/19 
mechanism or prevention. Applying the RCS model is helpful to determine the association between maternal age at childbirth and the ADHD and LD risks of offspring.

Although the present study results have some scientific significance, there are still several limitations of our study as a whole. First, genetic factors have a great influence on ADHD and LD risks. Even if we consider race as a covariate for adjustment and further analysis, we still cannot exclude the bias of genetic factors. Second, some maternal lifestyles during pregnancy also affect offspring ADHD and LD, although we adjusted for the variable of smoking during pregnancy. In fact, there are additional factors, such as gestational hypertension and gestational diabetes, but we cannot adjust for them because no such data are contained in the NHANES database. Third, in this study, some covariates were missing. To avoid reducing the sample size, we imputed data for the missing variables, but strictly speaking, this approach may have biased the actual results. Fourth, the outcome variables in this study based on selfreported data, leading to potential subjective bias. It is thus necessary for future research to use objective indicators.

In conclusion, the present study results indicated a U-shaped association between maternal age at childbirth and the ADHD and LD risk of offspring in a nationally representative U.S. survey. Future studies with large sample sizes and mechanistic studies are needed to confirm the risks of ADHD and LD.

\section{Declarations}

\section{Ethics approval and consent to participate}

Not applicable.

\section{Consent for publication}

Not applicable.

\section{Availability of data and materials}

The datasets generated and/or analyzed during the current study are publicly available from the Centers for Disease Control and Prevention (https://wwwn.cdc.gov/nchs/nhanes/Default.aspx).

\section{Competing interests}

The authors declare that they have no competing interests.

\section{Funding}


This work was supported by funding from the National Science Foundation of China (81903409).

\section{Authors' contributions}

YC, WWD and HBH designed and parametrized the mathematical model, conducted the analyses, and wrote the first draft of the article. SYM, and YC supported the model parameterization, conducted the statistical analyses, and participated in the drafting of the article. SYM and HBH conceived and led the design of the study and model and performed the analyses and drafting of the article. XMM revised the manuscript. All authors have read and approved the final article.

\section{Acknowledgements}

Not applicable.

\section{References}

1. Fall CH, Sachdev HS, Osmond C, Restrepo-Mendez MC, Victora C, Martorell R, Stein AD, Sinha S, Tandon N, Adair $\mathrm{L}$ et al: Association between maternal age at childbirth and child and adult outcomes in the offspring: a prospective study in five low-income and middle-income countries (COHORTS collaboration). The Lancet Global health 2015, 3(7):e366-377.

2. Rosendaal NTA, Pirkle CM: Age at first birth and risk of later-life cardiovascular disease: a systematic review of the literature, its limitation, and recommendations for future research. BMC public health 2017, 17(1):627.

3. Gibbs CM, Wendt A, Peters S, Hogue CJ: The impact of early age at first childbirth on maternal and infant health. Paediatric and perinatal epidemiology 2012, 26 Suppl 1:259-284.

4. Balasch J, Gratacos E: Delayed childbearing: effects on fertility and the outcome of pregnancy. Current opinion in obstetrics \& gynecology 2012, 24(3):187-193.

5. Lean SC, Derricott H, Jones RL, Heazell AEP: Advanced maternal age and adverse pregnancy outcomes: A systematic review and meta-analysis. PloS one 2017, 12(10):e0186287.

6. Carolan M, Frankowska D: Advanced maternal age and adverse perinatal outcome: a review of the evidence. Midwifery 2011, 27(6):793-801.

7. Carolan M: Maternal age $>/=45$ years and maternal and perinatal outcomes: a review of the evidence. Midwifery 2013, 29(5):479-489.

8. Merrill RM, Fugal S, Novilla LB, Raphael MC: Cancer risk associated with early and late maternal age at first birth. Gynecologic oncology 2005, 96(3):583-593.

9. Nassar AH, Usta IM: Advanced maternal age. Part II: long-term consequences. American journal of perinatology 2009, 26(2):107-112. 
10. Pariente G, Wainstock T, Walfisch A, Sheiner E, Harlev A: Advanced Maternal Age and the Future Health of the Offspring. Fetal diagnosis and therapy 2019, 46(2):139-146.

11. Hagan JF, Jr., Balachova T, Bertrand J, Chasnoff I, Dang E, Fernandez-Baca D, Kable J, Kosofsky B, Senturias YN, Singh N et al: Neurobehavioral Disorder Associated With Prenatal Alcohol Exposure. Pediatrics 2016, 138(4).

12. Lecendreux M, Konofal E, Faraone SV: Prevalence of attention deficit hyperactivity disorder and associated features among children in France. Journal of attention disorders 2011, 15(6):516-524.

13. Biederman J, Faraone SV, Spencer TJ, Mick E, Monuteaux MC, Aleardi M: Functional impairments in adults with self-reports of diagnosed ADHD: A controlled study of 1001 adults in the community. The Journal of clinical psychiatry 2006, 67(4):524-540.

14. Marshal MP, Molina BS: Antisocial behaviors moderate the deviant peer pathway to substance use in children with ADHD. Journal of clinical child and adolescent psychology : the official journal for the Society of Clinical Child and Adolescent Psychology, American Psychological Association, Division $532006,35(2): 216-226$.

15. Thapar A, Cooper M: Attention deficit hyperactivity disorder. Lancet 2016, 387(10024):1240-1250.

16. Sayal K, Prasad V, Daley D, Ford T, Coghill D: ADHD in children and young people: prevalence, care pathways, and service provision. The lancet Psychiatry 2018, 5(2):175-186.

17. Mhalla A, Guedria A, Brahem T, Amamou B, Sboui W, Gaddour N, Gaha L: ADHD in Tunisian Adolescents: Prevalence and Associated Factors. Journal of attention disorders 2018, 22(2):154-162.

18. Umar MU, Obindo JT, Omigbodun OO: Prevalence and Correlates of ADHD Among Adolescent Students in Nigeria. Journal of attention disorders 2018, 22(2):116-126.

19. Wang T, Liu K, Li Z, Xu Y, Liu Y, Shi W, Chen L: Prevalence of attention deficit/hyperactivity disorder among children and adolescents in China: a systematic review and meta-analysis. BMC psychiatry 2017, 17(1):32.

20. Altarac M, Saroha E: Lifetime prevalence of learning disability among US children. Pediatrics 2007, 119 Suppl 1:S77-83.

21. Padhy SK, Goel S, Das SS, Sarkar S, Sharma V, Panigrahi M: Prevalence and Patterns of Learning Disabilities in School Children. Indian journal of pediatrics 2016, 83(4):300-306.

22. Banaschewski T, Becker K, Dopfner M, Holtmann M, Rosler M, Romanos M: AttentionDeficit/Hyperactivity Disorder. Deutsches Arzteblatt international 2017, 114(9):149-159.

23. Roberts JL, Hovanes K, Dasouki M, Manzardo AM, Butler MG: Chromosomal microarray analysis of consecutive individuals with autism spectrum disorders or learning disability presenting for genetic services. Gene 2014, 535(1):70-78.

24. Becker N, Vasconcelos M, Oliveira V, Santos FCD, Bizarro L, Almeida RMM, Salles JF, Carvalho MRS: Genetic and environmental risk factors for developmental dyslexia in children: systematic review of the last decade. Developmental neuropsychology 2017, 42(7-8):423-445. 
25. Sciberras E, Mulraney M, Silva D, Coghill D: Prenatal Risk Factors and the Etiology of ADHD-Review of Existing Evidence. Current psychiatry reports 2017, 19(1):1.

26. Huang L, Wang Y, Zhang L, Zheng Z, Zhu T, Qu Y, Mu D: Maternal Smoking and AttentionDeficit/Hyperactivity Disorder in Offspring: A Meta-analysis. Pediatrics 2018, 141(1).

27. Johnson EO, Breslau N: Increased risk of learning disabilities in low birth weight boys at age 11 years. Biological psychiatry 2000, 47(6):490-500.

28. Andersen $\mathrm{CH}$, Thomsen $\mathrm{PH}$, Nohr EA, Lemcke S: Maternal body mass index before pregnancy as a risk factor for ADHD and autism in children. European child \& adolescent psychiatry 2018, 27(2):139148.

29. Wiegersma AM, Dalman C, Lee BK, Karlsson H, Gardner RM: Association of Prenatal Maternal Anemia With Neurodevelopmental Disorders. JAMA psychiatry 2019:1-12.

30. Gallo EF, Posner J: Moving towards causality in attention-deficit hyperactivity disorder: overview of neural and genetic mechanisms. The lancet Psychiatry 2016, 3(6):555-567.

31. Hvolgaard Mikkelsen S, Olsen J, Bech BH, Obel C: Parental age and attention-deficit/hyperactivity disorder (ADHD). International journal of epidemiology 2017, 46(2):409-420.

32. Mahone EM, Denckla MB: Attention-Deficit/Hyperactivity Disorder: A Historical Neuropsychological Perspective. Journal of the International Neuropsychological Society : JINS 2017, 23(9-10):916-929.

33. Matthews TJ, Hamilton BE: First births to older women continue to rise. NCHS data brief 2014(152):18.

34. Sheen JJ, Wright JD, Goffman D, Kern-Goldberger AR, Booker W, Siddiq Z, D'Alton ME, Friedman AM: Maternal age and risk for adverse outcomes. American journal of obstetrics and gynecology 2018, 219(4):390 e391-390 e315.

35. Chang Z, Lichtenstein P, D'Onofrio BM, Almqvist C, Kuja-Halkola R, Sjolander A, Larsson H: Maternal age at childbirth and risk for ADHD in offspring: a population-based cohort study. International journal of epidemiology 2014, 43(6):1815-1824.

36. Faraone SV, Asherson P, Banaschewski T, Biederman J, Buitelaar JK, Ramos-Quiroga JA, Rohde LA, Sonuga-Barke EJ, Tannock R, Franke B: Attention-deficit/hyperactivity disorder. Nature reviews Disease primers 2015, 1:15020.

37. Tarver J, Daley D, Sayal K: Attention-deficit hyperactivity disorder (ADHD): an updated review of the essential facts. Child: care, health and development 2014, 40(6):762-774.

38. Whitsell LJ: Learning disorders as a school health problem. Neurological and psychiatric aspects. California medicine 1969, 111(6):433-445.

39. Erenberg G: Learning disabilities: an overview. Seminars in neurology 1991, 11(1):1-6.

40. Barclay KaM, M.: Advanced Maternal Age and Offspring Outcomes: Reproductive Aging and Counterbalancing Period Trends. . Population and Development Review 2016, 42:69-94.

41. Goldmann JM, Seplyarskiy VB, Wong WSW, Vilboux T, Neerincx PB, Bodian DL, Solomon BD, Veltman JA, Deeken JF, Gilissen C et al: Germline de novo mutation clusters arise during oocyte aging in 
genomic regions with high double-strand-break incidence. Nature genetics 2018, 50(4):487-492.

42. May-Panloup P, Boucret L, Chao de la Barca JM, Desquiret-Dumas V, Ferre-L'Hotellier V, Moriniere C, Descamps P, Procaccio V, Reynier P: Ovarian ageing: the role of mitochondria in oocytes and follicles. Human reproduction update 2016, 22(6):725-743.

43. Miao YL, Kikuchi K, Sun QY, Schatten H: Oocyte aging: cellular and molecular changes, developmental potential and reversal possibility. Human reproduction update 2009, 15(5):573-585.

44. McKinnon PJ: Genome integrity and disease prevention in the nervous system. Genes \& development 2017, 31(12):1180-1194.

45. Khacho M, Harris R, Slack RS: Mitochondria as central regulators of neural stem cell fate and cognitive function. Nature reviews Neuroscience 2019, 20(1):34-48.

46. Graham HR, Minhas RS, Paxton G: Learning Problems in Children of Refugee Background: A Systematic Review. Pediatrics 2016, 137(6).

47. Mao WJ, Wu ZY, Yang ZH, Xu YW, Wang SQ: Advanced maternal age impairs spatial learning capacity in young adult mouse offspring. American journal of translational research 2018, 10(3):975988.

48. Sampino S, Stankiewicz AM, Zacchini F, Goscik J, Szostak A, Swiergiel AH, Drago G, Modlinski JA, Ptak GE: Pregnancy at Advanced Maternal Age Affects Behavior and Hippocampal Gene Expression in Mouse Offspring. The journals of gerontology Series A, Biological sciences and medical sciences 2017, 72(11):1465-1473.

49. Cimadomo D, Fabozzi G, Vaiarelli A, Ubaldi N, Ubaldi FM, Rienzi L: Impact of Maternal Age on Oocyte and Embryo Competence. Frontiers in endocrinology 2018, 9:327.

50. Fergusson DM, Woodward LJ: Maternal age and educational and psychosocial outcomes in early adulthood. Journal of child psychology and psychiatry, and allied disciplines 1999, 40(3):479-489.

51. Wang MH, vom Saal FS: Maternal age and traits in offspring. Nature 2000, 407(6803):469-470.

52. Herting MM, Gautam P, Spielberg JM, Kan E, Dahl RE, Sowell ER: The role of testosterone and estradiol in brain volume changes across adolescence: a longitudinal structural MRI study. Human brain mapping 2014, 35(11):5633-5645.

\section{Figures}




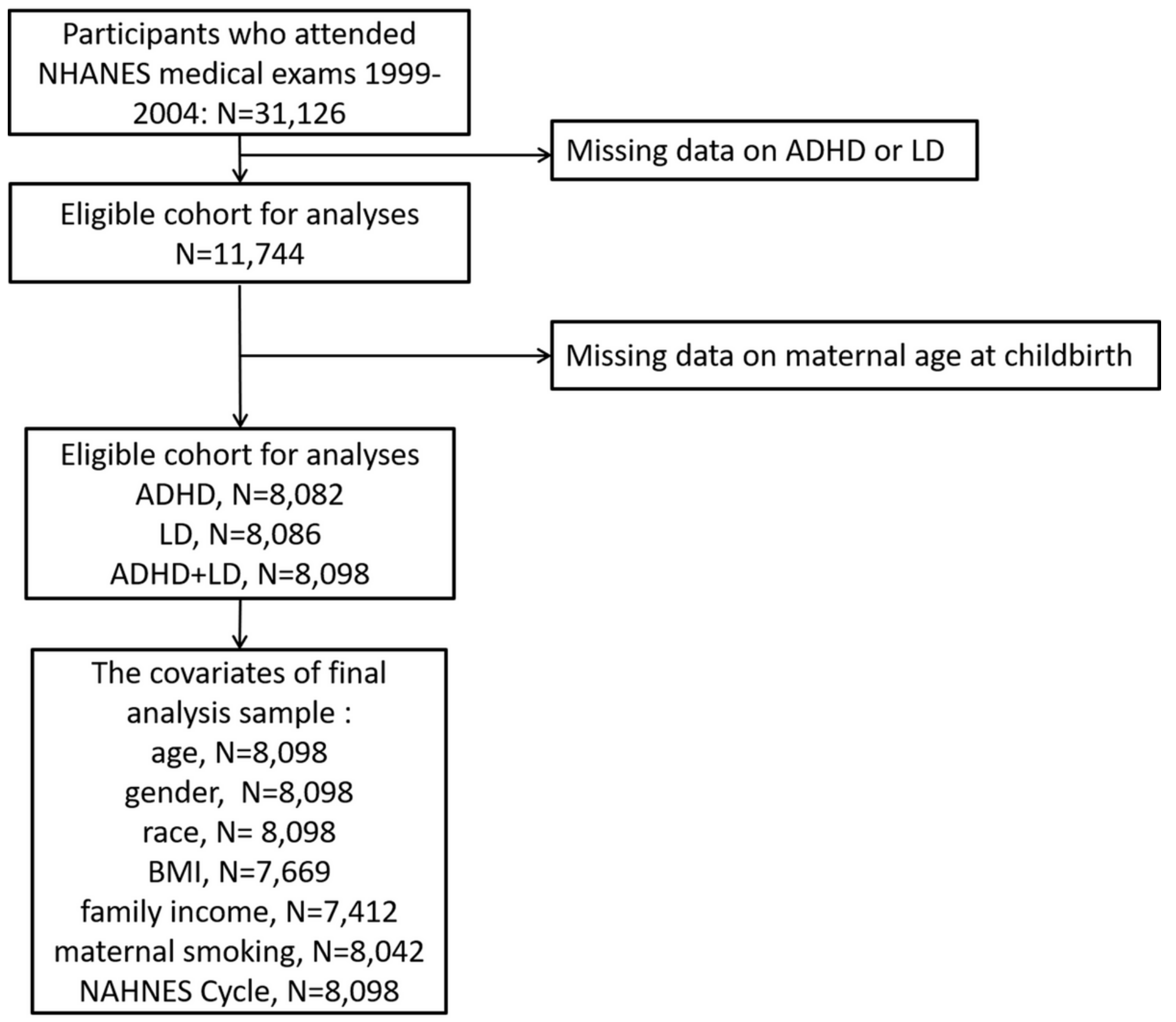

Figure 1

Eligible participants and those included in the analyses of the associations between maternal age at childbirth and the ADHD and LD risk of offspring in the U.S. population. 

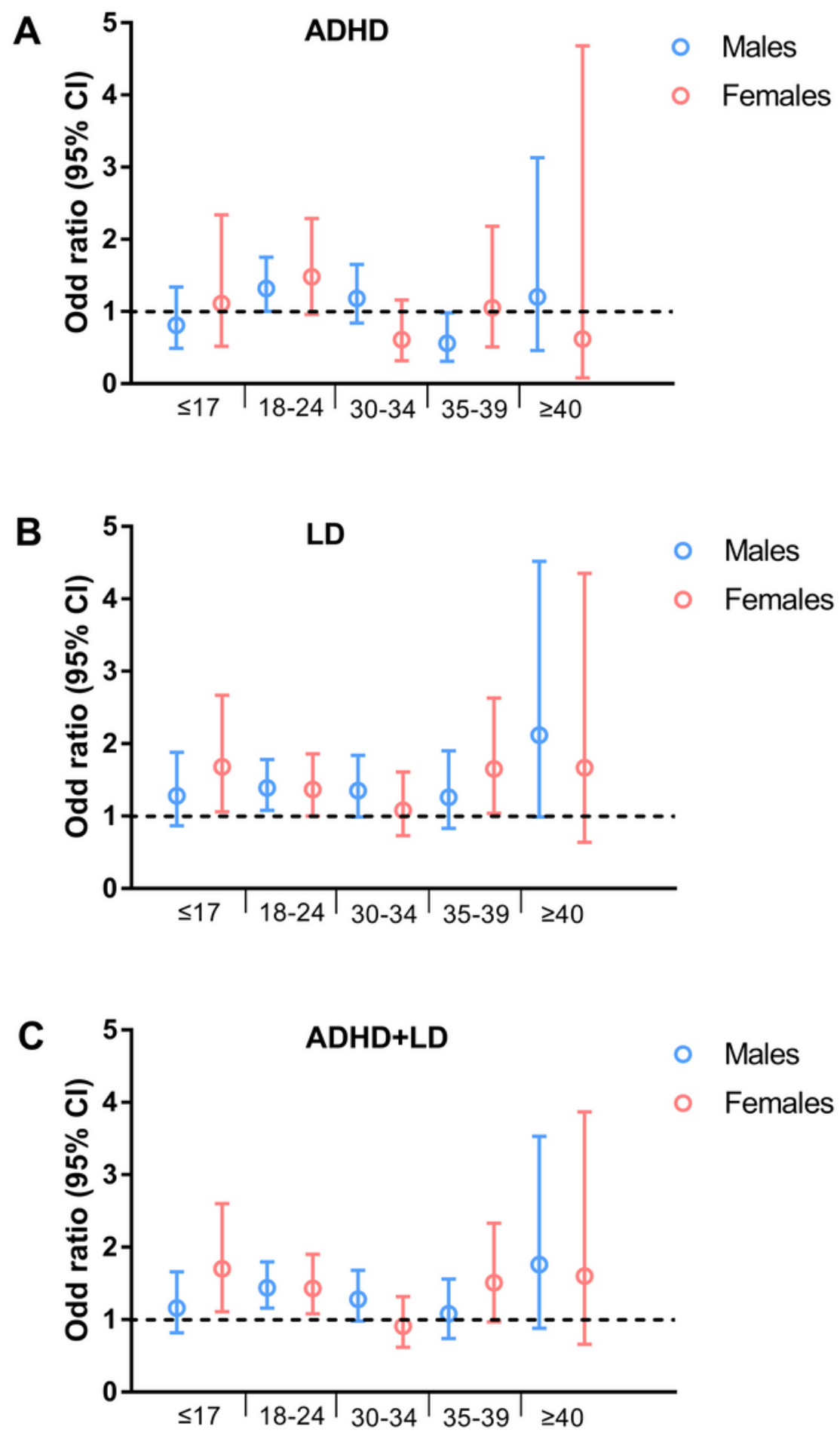

Figure 2

ORs and 95\% Cls for ADHD (A), LD (B) and ADHD+LD (C) risk for the different age groups compared with subjects aged 25-29 years stratified by gender: children and adolescents aged $4-15$ years, National Health and Nutrition Examination Survey, 1999-2004. ADHD, attention-deficit/hyperactivity disorder. LD, learning disability. $\mathrm{Cl}$, confidence interval. 

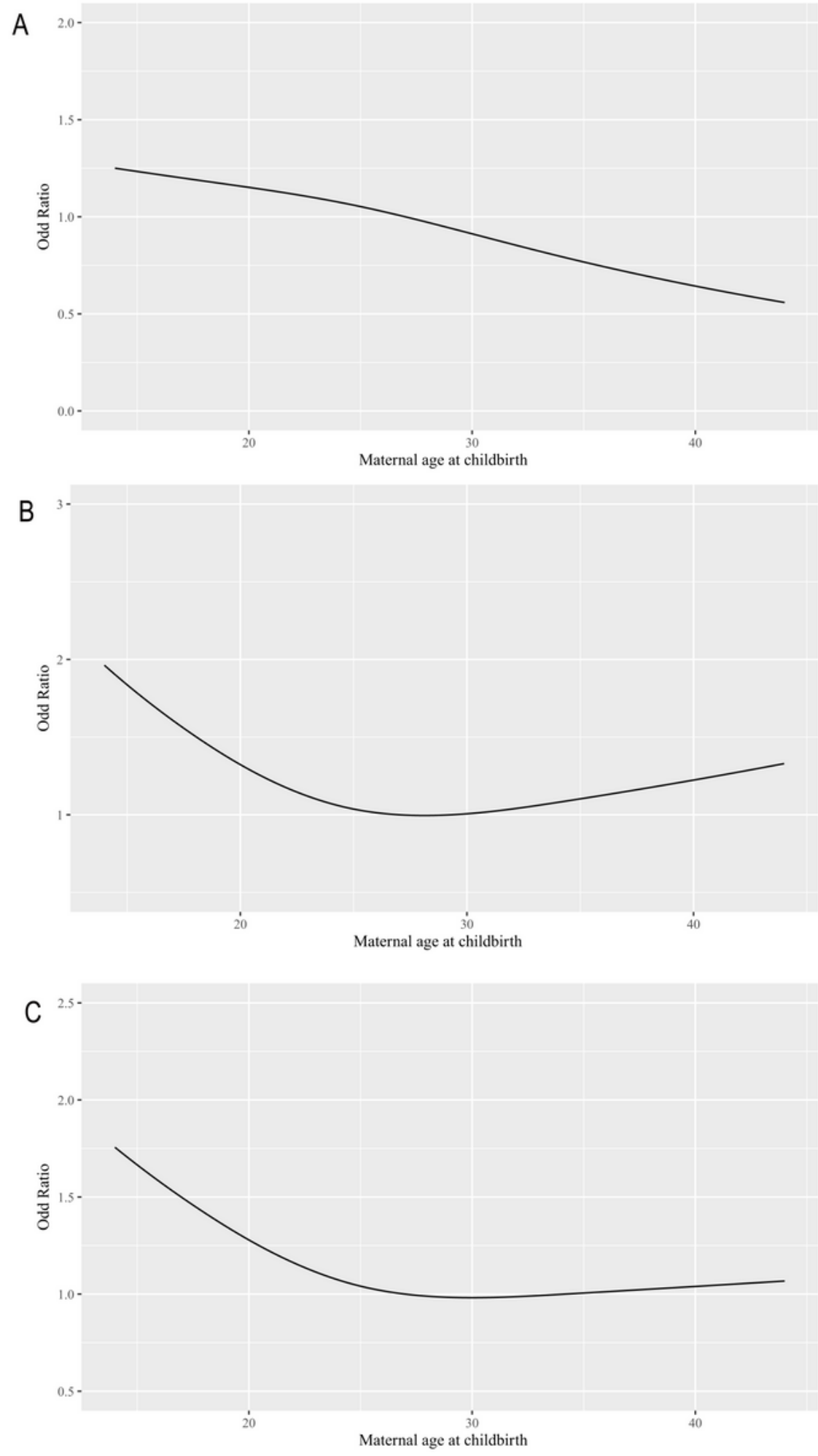

\section{Figure 3}

Predicted spline curves for the associations of maternal age at childbirth with the risk of ADHD (A), LD (B) and ADHD+LD (C) according to RCS regression models. ADHD, attention-deficit/hyperactivity disorder. LD, learning disability.

\section{Supplementary Files}


This is a list of supplementary files associated with this preprint. Click to download.

- TableS1.docx

- supplementmaterials.docx 